УДК 697.329:006.354

\title{
АНАЛИЗ НОРМАТИВНЫХ ТРЕБОВАНИЙ К СИСТЕМАМ СЛЕЖЕНИЯ ЗА СОЛНЦЕМ ДЛЯ АВТОНОМНЫХ ФОТОЭНЕРГОУСТАНОВОК
}

\author{
Андрианова Людмила Прокопьевна \\ д-р техн. наук, профессор \\ Рябишина Лилия Амировна \\ канд. техн. наук, доцент \\ Хазиева Регина Тагировна \\ канд. техн. наук, доцент \\ Уфимский государственный нефтяной \\ технический университет
}

Аннотация: В работе рассматриваются нормативные требования, предъявляемые к системам слежения за Солнцем для применения в автономных энергетических установках с фотоэлектрическими модулями. Систематизированы и представлены в табличном виде: понятийный аппарат; классы систем слежения за Солнцем и их основные характеристики, указываемые в технической документации применительно к таким категориям, как условия окружающей среды, точность слежения, устанавливаемое оборудование, энергопотребление, системы электропривода, системы управления, монтажные характеристики, показатели надежности. Рассмотрены способы ориентация приемной поверхности фотоэлектрического модуля по отношению к оси системы слежения за Солнцем для одноосных (однокоординатных) и двухосных (двухкоординатных) систем слежения. В качестве примера приведена оригинальная конструкция крышной солнечной микрофотоэлектростанции с азимутальным и зенитальным слежением за Солнцем. Рассмотрены параметры систем слежения за Солнцем: допуски по положению основной оси и дополнительной оси, люфты, жесткость, диапазон перемещения и мгновенная ошибка наведения. Представлен нормативный упрощенный алгоритм определения диапазона точности слежения за Солнцем на основе оценки «Медианная точность слежения: лучшая - худшая».

Ключевые слова: Фотоэлектрические системы, системы слежения за Солнцем, одноосные и двухосные системы слежения, мгновенная ошибка 
наведения системы слежения, типовой диапазон точности системы слежения, виды и способы систем управления, приведение в действие системы слежения.

\title{
ANALYSIS OF REGULATORY REQUIREMENTS FOR SOLAR TRACKING SYSTEMS FOR AUTONOMOUS PHOTOELECTRIC POWER PLANTS
}

\section{Andrianova Lyudmila Prokopyevna Ryabishina Lilia Amirovna Khazieva Regina Tagirovna}

\begin{abstract}
The paper considers the regulatory requirements for solar tracking systems for use in autonomous power plants with photovoltaic modules. Systematized and presented in tabular form: conceptual apparatus; classes of solar tracking systems and their main characteristics, specified in the technical documentation in relation to such categories as environmental conditions, tracking accuracy, installed equipment, energy consumption, electric drive systems, control systems, installation characteristics, reliability indicators. The methods of orientation of the receiving surface of the photovoltaic module with respect to the axis of the solar tracking system for uniaxial (single-coordinate) and biaxial (two-coordinate) tracking systems are considered. As an example, the original design of a roofmounted solar microphotoelectric power station with azimuthal and zenithal tracking of the Sun is given. The parameters of the Sun tracking systems are considered: the tolerances for the position of the main axis and the additional axis, backlash, stiffness, range of movement and instantaneous guidance error. A standard simplified algorithm for determining the range of accuracy of tracking the Sun based on the assessment "Median tracking accuracy: best - worst" is presented.
\end{abstract}

Key words: Photovoltaic systems, solar tracking systems, uniaxial and biaxial tracking systems, instantaneous guidance error of the tracking system, typical accuracy range of the tracking system, types and methods of control systems, actuation of the tracking system.

«Система слежения за Солнцем - это комплекс устройств и механизмов, обеспечивающий за счет следования за движением Солнца по небосводу точно заданное положение приемных поверхностей фотоэлектрических устройств относительно Солнца и тем самым увеличение солнечного излучения, 
поступающего на приемные поверхности». Такое определение дано в ГОСТ Р 57229-2016 (МЭК 62817: 2014) «Системы фотоэлектрические Устройства слежения за Солнцем. Технические условия» [1, с. 3]. Основные термины в области фотоэлектрических систем с соответствующими определениями приведены в таблице 1 в соответствии с [1, с. 4].

Таблица 1

\section{Термины и определения}

\begin{tabular}{|c|c|}
\hline & $\begin{array}{l}\text { Фотоэлектрическая система - система, преобразующая солнечную энергию в } \\
\text { электрическую с помощью прямого преобразования и использующая ее для частичного } \\
\text { или полного покрытия электрических нагрузок потребителя и/или передачи ее в сеть. } \\
\text { Допустимые термины: "Солнечная фотоэлектрическая станция; СФЭС", "Солнечная } \\
\text { электростанция; СЭС". }\end{array}$ \\
\hline 2 & $\begin{array}{l}\text { Фотоэлектрическое устройство- устройство, в котором энергия солнечного } \\
\text { излучения преобразуется в электрическую энергию на основе фотоэффекта. }\end{array}$ \\
\hline 3 & $\begin{array}{l}\text { Фотоэлектрический элемент - наименьший неделимый преобразователь энергии } \\
\text { солнечного излучения в электрическую энергию на основе фотоэффекта. } \\
\text { Допустимые термины: } \\
\text { "Солнечный фотоэлектрический элемент", } \\
\text { "Солнечный элемент", "Фотоэлектрический преобразователь", } \\
\text { "Фотопреобразователь" } \\
\text { Фотоэлектрический элемент может также преобразовывать иное } \\
\text { электромагнитное излучение. }\end{array}$ \\
\hline 4 & $\begin{array}{l}\text { Фотоэлектрический модуль (ФМ) - устройство, конструктивно объединяющее } \\
\text { электрически соединенные между собой фотоэлектрические элементы, защищенное от } \\
\text { окружающей среды и допускающее испытания и эксплуатацию в качестве независимой } \\
\text { конструкционной единицы. } \\
\text { Допустимый термин в соответствии с ГОСТ Р } 51597 \text { [2] :"Фотоэлектрический } \\
\text { солнечный модуль (ФСМ) }\end{array}$ \\
\hline 5 & $\begin{array}{l}\text { Фотоэлектрические устройства с концентраторами - фотоэлектрические устройства, } \\
\text { в которых происходит изменение пространственного распределения и/или повышение } \\
\text { плотности потока солнечного излучения, в результате чего в электрическую энергию } \\
\text { преобразуется концентрированное излучение. }\end{array}$ \\
\hline 6 & $\begin{array}{l}\text { Фотоэлектрическая батарея (ФБ) - устройство, состоящее из электрически } \\
\text { соединенных фотоэлектрических модулей, фотоэлектрических цепочек или } \\
\text { фотоэлектрических групп, генерирующее постоянный электрический ток под } \\
\text { воздействием электромагнитного излучения и включающее также все компоненты, } \\
\text { обеспечивающие электрические и механические соединения внутри батареи и с } \\
\text { внешними устройствами, конструкциями. } \\
\text { 1. Под ФБ понимаются все ее составляющие до входных зажимов постоянного тока }\end{array}$ \\
\hline
\end{tabular}




\begin{tabular}{|c|l|}
\hline \hline & $\begin{array}{l}\text { преобразователя энергии, накопителя энергии или нагрузки постоянного тока. } \\
\text { Границей ФБ считается выходная сторона отключающего устройства ФБ. } \\
\text { 2. ФБ может состоять из единственного фотоэлектрического модуля, отдельной } \\
\text { фотоэлектрической цепочки, или нескольких параллельно соединенных } \\
\text { фотоэлектрических иепочек, или нескольких параллельно соединенных } \\
\text { фотоэлектрических групп и их соответствующих компонентов. }\end{array}$ \\
\hline 7 & $\begin{array}{l}\text { Приемная поверхность - поверхность фотоэлектрического } \\
\text { устройства/фотоэлектрической части устройства, на которую поступает солнечное } \\
\text { излучение. }\end{array}$ \\
\hline 8 & $\begin{array}{l}\text { Плоскость приемных поверхностей - плоскость, в которой расположены приемные } \\
\text { поверхности фотоэлектрических модулей, установленных на системе слежения за } \\
\text { Солнцем. }\end{array}$ \\
\hline 9 & Слежение - ориентация с постоянной стабилизированной скоростью. \\
\hline 10 & $\begin{array}{l}\text { Медианная точность системы слежения за Солнцем - медианное значение ошибки } \\
\text { наведения по отобранным данным. } \\
\text { Все зарегистрированные ошибки наведения будут иметь положстельные значения, } \\
\text { соответственно "медианная точность" будет больше нуля и меньше } \\
\text { 95-го процентиля точности. }\end{array}$ \\
\hline 11 & $\begin{array}{l}\text { 95-й процентиль точности системы слежения за Солнцем - значение 95-го } \\
\text { процентиля ошибки наведения по набору отобранных данных (95\% измеренных данных } \\
\text { мгновенной ошибки наведения будут ниже этого значения). }\end{array}$ \\
\hline
\end{tabular}

Минимальные требования к системам слежения за Солнцем, обеспечивающие полноту информации о конкретной системе слежения за Солнцем, установлены в ГОСТ Р 57229-2016 (МЭК 62817: 2014) [1]:

- методы испытаний систем слежения за Солнцем в целом и их основных компонентов;

- способы измерения и расчета параметров, указываемых в паспортных данных конкретной системы слежения за Солнцем;

- методы испытаний для определения соответствия характеристик систем слежения за Солнцем требуемым значениям;

- методы испытаний для выявления конструкций систем слежения за Солнцем, имеющих высокую вероятность отказов в отличие от конструкций, способных выполнять свои функции в соответствии с технической документацией с высокой надежностью.

В стандарте [1, с. 5] отмечается, что «Результаты механических испытаний не распространяются на фундамент и части строительных конструкций, к которым крепится испытуемая система слежения за Солнцем, 


\section{ИННОВАЦИОННОЕ РАЗВИТИЕ НАУКИ: ФУНДАМЕНТАЛЬНЫЕ И ПРИКЛАДНЫЕ ПРОБЛЕМЫ}

поскольку такой тип соответствия определяется также строительными нормами, правилами и особенностями места установки, например, типами почвы и т.п.»

В соответствии с ГОСТ Р Р 57229-2016 (МЭК 62817: 2014) системы слежения за Солнцем, предназначенные для применения в фотоэлектрических системах, подразделяют на два основных класса:

- системы слежения за Солнцем для размещения плоских фотоэлектрических модулей;

- системы слежения за Солнцем для размещения фотоэлектрических модулей с концентраторами.

Каждый из этих классов систем слежения за Солнцем разделен на категории по количеству и направлению осей, компоновочным решениям исполнительных механизмов, типам приводов, климатическому исполнению, типу вертикального монтажа и фундамента, типу управления, типу формирования сигнала о направлении на Солнце и по другим характеристикам, приведенным в таблице 2 .

Таблица 2

Классификация систем слежения за Солнцем

\begin{tabular}{|l|l|}
\hline $\begin{array}{l}\text { Классификационный признак } \\
\text { систем }\end{array}$ & Виды систем \\
\hline $\begin{array}{l}\text { Количество направлений осей } \\
\text { вращения: }\end{array}$ & Одноосные и двуосные \\
\hline Одноосные: & $\begin{array}{l}\text { - с горизонтальной осью; } \\
\text { - с вертикальной осью; } \\
\text { - наклонные. }\end{array}$ \\
\hline Двуосные: & $\begin{array}{l}\text { - горизонтальной основной осью; } \\
\text { - с вертикальной основной осью; } \\
\text { - с наклонной основной осью. }\end{array}$ \\
\hline Тип привода & - с электроприводом; \\
- с гидроприводом; \\
- с пассивным приводом.
\end{tabular}




\begin{tabular}{|l|l|}
\hline Место установки & - на земле; \\
& - на воде; \\
& - на здании (крыше, стене) или другом объекте; \\
& - интегрированные в здание/объект. \\
\hline Тип фундамента & - на фундаменте глубокого залегания; \\
& - на поверхностном фундаменте. \\
\hline
\end{tabular}

Примеры указания характеристик систем слежения за Солнцем в технической документации приведены в таблице 3.

\section{Таблица 3}

\section{Примеры указания характеристик систем слежения за Солнцем}

\begin{tabular}{|c|c|c|}
\hline Характеристика & $\begin{array}{c}\text { Пример указания характеристик } \\
\text { в технической документации }\end{array}$ & Кем определяется \\
\hline Изготовитель & Компания АБВ & $\begin{array}{c}\text { Определяется изготовителем и } \\
\text { подтверждается } \\
\text { Номер модели }\end{array}$ \\
\cline { 1 - 2 } $\begin{array}{c}\text { Тип системы } \\
\text { слежения за } \\
\text { Солнцем }\end{array}$ & $\begin{array}{c}\text { Система слежения за Солнцем } \\
\text { для размещения } \\
\text { фотоэлектрического модуля с } \\
\text { концентратором, двухосное }\end{array}$ \\
\hline
\end{tabular}

Требования, предъявляемые к основным характеристикам систем слежения за Солнцем, рассматриваемые по категории «Условия окружающей среды», приведены в таблице 4.

Таблица 4

\section{Основные характеристики условий окружающей среды}

\begin{tabular}{|c|c|c|}
\hline $\begin{array}{l}\text { № } \\
\text { ПП }\end{array}$ & Характеристика & $\begin{array}{l}\text { Пример указания характеристик } \\
\text { в технической документации }\end{array}$ \\
\hline 1 & $\begin{array}{l}\text { Максимальная допустимая скорость ветра в режиме } \\
\text { слежения }\end{array}$ & $14 \mathrm{~m} / \mathrm{c}$ \\
\hline 2 & $\begin{array}{l}\text { Максимальная допустимая скорость ветра в } \\
\text { штормовом положении }\end{array}$ & $40 \mathrm{M} / \mathrm{c}$ \\
\hline 3 & Диапазон рабочей температуры & От - 20 до $+50^{\circ} \mathrm{C}$ \\
\hline 4 & Диапазон допустимой температуры & От - 40 до $+60^{\circ} \mathrm{C}$ \\
\hline 5 & Снегостойкость & $\begin{array}{l}\text { Допускается до } 20 \text { кг/м }{ }^{2} \text { снеговой } \\
\text { нагрузки }\end{array}$ \\
\hline
\end{tabular}


Требования, предъявляемые к основным характеристикам систем слежения за Солнцем, рассматриваемые по категории «Точность слежения», приведены в таблице 5.

\section{Таблица 5}

\section{Основные характеристики точности слежения}

\begin{tabular}{|c|c|c|}
\hline $\begin{array}{l}\text { № } \\
\text { ПП }\end{array}$ & Характеристика & $\begin{array}{c}\text { Пример указания характеристик } \\
\text { в технической документации }\end{array}$ \\
\hline 1 & \begin{tabular}{|l} 
Точность, медианная \\
(слабый ветер, наименьшее отклонение)
\end{tabular} & $0,1^{\circ}$ \\
\hline 2 & $\begin{array}{l}\text { Точность, медианная } \\
\text { (слабый ветер, наибольшее отклонение) }\end{array}$ & $0,3^{\circ}$ \\
\hline 3 & $\begin{array}{l}\text { Точность, 95-й процентиль } \\
\text { (слабый ветер, наименьшее отклонение) }\end{array}$ & $0,5^{\circ}$ \\
\hline 4 & $\begin{array}{l}\text { Точность, 95-й процентиль } \\
\text { (слабый ветер, наибольшее отклонение) }\end{array}$ & $0,8^{\circ}$ \\
\hline 5 & $\begin{array}{l}\text { Средняя скорость ветра во время испытаний в } \\
\text { условиях "слабого ветра" }\end{array}$ & $3,1 \mathrm{~m} / \mathrm{c}$ \\
\hline 6 & $\begin{array}{l}\text { Точность, медианная } \\
\text { (сильный ветер, наименьшее отклонение) }\end{array}$ & $0,7^{\circ}$ \\
\hline 7 & $\begin{array}{l}\text { Точность, медианная } \\
\text { (сильный ветер, наибольшее отклонение) }\end{array}$ & $1,0^{\circ}$ \\
\hline 8 & $\begin{array}{l}\text { Точность, 95-й процентиль } \\
\text { (сильный ветер, наименьшее отклонение) }\end{array}$ & $1,1^{\circ}$ \\
\hline 9 & $\begin{array}{l}\text { Точность, 95-й процентиль } \\
\text { (сильный ветер, наибольшее отклонение) }\end{array}$ & $1,6^{\circ}$ \\
\hline 10 & $\begin{array}{l}\text { Средняя скорость ветра во время испытаний в } \\
\text { условиях "сильного ветра" }\end{array}$ & $5,2 \mathrm{M} / \mathrm{c}$ \\
\hline 11 & $\begin{array}{l}\text { Вес и площадь, установленного } \\
\text { испытательного } \\
\text { оборудования }\end{array}$ & $\begin{array}{c}\text { Нагрузка } 500 \text { кг, равномерно } \\
\text { размещенная по площади } 50 \mathrm{M}^{2}\end{array}$ \\
\hline 12 & $\begin{array}{l}\text { Центр тяжести установленного } \\
\text { испытательного } \\
\text { оборудования }\end{array}$ & $\begin{array}{c}\text { Центр тяжести оборудования } \\
\text { расположен на 0,2 м выше } \\
\text { поверхности, на которую } \\
\text { устанавливают } \\
\text { фотоэлектрические модули }\end{array}$ \\
\hline
\end{tabular}

Требования, предъявляемые к основным характеристикам систем слежения за Солнцем, рассматриваемые по категории «Устанавливаемое оборудование», приведены в таблице 6 . 
Таблица 6

Основные характеристики устанавливаемого оборудования

\begin{tabular}{|c|l|l|}
\hline $\begin{array}{c}\text { № } \\
\text { пп }\end{array}$ & Характеристика & $\begin{array}{l}\text { Пример указания характеристик } \\
\text { в технической документации }\end{array}$ \\
\hline 1 & Минимальная / максимальная масса & 100 кг / 1025 кг \\
\hline 2 & Ограничения на смещение центра масс & не более 0,3 м по вертикали \\
\hline 3 & Максимальная площадь & $30 \mathrm{~m}^{2}$ \\
\hline 4 & Номинальная площадь & $28 \mathrm{~m}^{2}$ \\
\hline 5 & $\begin{array}{l}\text { Максимальные допустимые динамические } \\
\text { моменты во время движения }\end{array}$ & $\begin{array}{l}\text { Азимут, ось } \mathrm{z}-10 \text { кН·м; } \\
\text { оси х, у - 5 кН·м. } \\
\text { Для уточнения моментов должен } \\
\text { быть представлен набор } \\
\text { диарамм относительно каждой } \\
\text { из осей вращения }\end{array}$ \\
\hline 6 & $\begin{array}{l}\text { Максимальные допустимые статические моменты } \\
\text { в штормовом положении }\end{array}$ & $\begin{array}{l}\text { Должен быть представлен набор } \\
\text { диаграмм }\end{array}$ \\
\hline
\end{tabular}

Требования, предъявляемые к основным характеристикам систем слежения за Солнцем, рассматриваемые по категории «Электрические характеристики», приведены в таблице 7.

Таблица 7

\section{Электрические характеристики систем слежения за Солнцем}

\begin{tabular}{|c|c|c|}
\hline $\begin{array}{l}\text { № } \\
\text { ПП }\end{array}$ & Характеристика & $\begin{array}{l}\text { Пример указания характеристик } \\
\text { в технической документации }\end{array}$ \\
\hline 1 & Дневное потребление электроэнергии & $1,5 \mathrm{\kappa BT} \cdot ч$ \\
\hline 2 & $\begin{array}{l}\text { Потребление электроэнергии в штормовом } \\
\text { положении }\end{array}$ & 1 кВТ $\cdot$ ч \\
\hline 3 & Питание & $\begin{array}{l}\text { Переменный ток, } \\
\text { 100-240 В, 50Гц, } 5 \text { А }\end{array}$ \\
\hline 4 & $\begin{array}{l}\text { Максимальная потребляемая активная (полная) } \\
\text { мощность в режиме слежения }\end{array}$ & $500 \mathrm{BT}(550 \mathrm{~B} \cdot \mathrm{A})$ \\
\hline 5 & $\begin{array}{l}\text { Максимальная потребляемая активная (полная) } \\
\text { мощность не в режиме слежения }\end{array}$ & 50 Вт $(55 \mathrm{~B} \cdot \mathrm{A})$ \\
\hline 6 & $\begin{array}{l}\text { Максимальная потребляемая активная (полная) } \\
\text { мощность при переводе в штормовое положение }\end{array}$ & 1000 Вт $(1100 \mathrm{~B} \cdot \mathrm{A})$ \\
\hline 7 & Резервное электропитание & нет \\
\hline
\end{tabular}




\section{ИННОВАЦИОННОЕ РАЗВИТИЕ НАУКИ: ФУНДАМЕНТАЛЬНЫЕ И ПРИКЛАДНЫЕ ПРОБЛЕМЫ}

Требования, предъявляемые к основным характеристикам систем слежения за Солнцем, рассматриваемые по категории «Система привода», приведены в таблице 8 .

Таблица 8

Основные характеристики систем электропривода

\begin{tabular}{|c|c|c|}
\hline $\begin{array}{l}\text { № } \\
\text { ПП }\end{array}$ & Характеристика & $\begin{array}{l}\text { Пример указания характеристик } \\
\text { в технической документации }\end{array}$ \\
\hline 1 & Тип управления & Индивидуальное \\
\hline 2 & Тип привода & Электрический \\
\hline 3 & Исполнительные устройства & Двигатели постоянного тока, 185 Вт \\
\hline 4 & $\begin{array}{l}\text { Диапазон перемещения, } \\
\text { основная ось }\end{array}$ & $\pm 160^{\circ}$ по азимуту \\
\hline 5 & $\begin{array}{l}\text { Диапазон перемещения, } \\
\text { дополнительная ось } \\
\end{array}$ & От $10^{\circ}$ до $90^{\circ}$ по высоте \\
\hline 6 & Жесткость & $\begin{array}{l}\text { Определяется по протоколу лабораторных испытаний, } \\
\text { в котором приведены места выполнения измерений, } \\
\text { приложенные нагрузки и измеренные отклонения }\end{array}$ \\
\hline 7 & $\begin{array}{l}\text { Крутильная жесткость } \\
\text { трансмиссии }\end{array}$ & $\begin{array}{l}\text { Определяется по графику углового рассогласования в } \\
\text { зависимости от приложенного момента }\end{array}$ \\
\hline 8 & Люфт & Не более 2,5 мм \\
\hline
\end{tabular}

Требования, предъявляемые к основным характеристикам систем слежения за Солнцем, рассматриваемые по категории «Характеристики системы управления», приведены в таблице 9.

Таблица 9

\section{Основные характеристики системы управления}

\begin{tabular}{|c|l|l|}
\hline $\begin{array}{c}\text { № } \\
\text { пп }\end{array}$ & Характеристика & $\begin{array}{l}\text { Пример указания характеристик } \\
\text { в технической документации }\end{array}$ \\
\hline 1 & Тип управления & Смешанный \\
\hline 2 & Сопряжение системы управления & Отсутствует \\
\hline 3 & Внешнее сопряжение & Локальная сеть Ethernet, TCP/IP \\
\hline 4 & $\begin{array}{l}\text { Режим приведения в штормовое } \\
\text { положение }\end{array}$ & Включается при скорости ветра 14 м/с \\
\hline 5 & Время приведения в штормовое положение & 4 мин \\
\hline 6 & Рассогласование таймера & 1 с в год \\
\hline 7 & Слежение & Непрерывное \\
\hline 8 & Тип датчиков & Датчик положения Солнца \\
\hline 9 & Концевые выключатели & Не установлены \\
\hline
\end{tabular}




\section{ИННОВАЦИОННОЕ РАЗВИТИЕ НАУКИ: ФУНДАМЕНТАЛЬНЫЕ И ПРИКЛАДНЫЕ ПРОБЛЕМЫ}

Требования, предъявляемые к основным характеристикам систем слежения за Солнцем, рассматриваемые по категории «Монтажные характеристики», приведены в таблице 10.

Таблица 10

Монтажные характеристики

\begin{tabular}{|c|l|l|}
\hline $\begin{array}{c}\text { № } \\
\text { пп }\end{array}$ & Характеристика & $\begin{array}{l}\text { Пример указания характеристик } \\
\text { в технической документации }\end{array}$ \\
\hline 1 & Фундамент & Железобетон \\
\hline 2 & Допуск по основной оси & $\pm 0,5^{\circ}$ \\
\hline 3 & Допуск по дополнительной оси & $\pm 0,5^{\circ}$ \\
\hline 4 & $\begin{array}{l}\text { Допустимые варианты присоединения } \\
\text { установленного оборудования }\end{array}$ & $\begin{array}{l}\text { Крепление рассчитано на установку } \\
\text { фотоэлектрических модулей изготовителей } \\
\text { "А", "Б" и "В". Допускается болтовое } \\
\text { крепление в конфигурации "Г, "Д" и "Е" }\end{array}$ \\
\hline 5 & Необходимые ресурсы & 5 чел-час, грузоподъемная техника \\
\hline
\end{tabular}

Требования, предъявляемые к основным характеристикам систем слежения за Солнцем, рассматриваемые по категории «обслуживание и показатели надежности», приведены в таблице 11.

\section{Таблица 11}

Обслуживание и показатели надежности

\begin{tabular}{|c|l|l|}
\hline $\begin{array}{c}\text { № } \\
\text { пா }\end{array}$ & Характеристика & $\begin{array}{l}\text { Пример указания характеристик } \\
\text { в технической документации }\end{array}$ \\
\hline 1 & Расписание обслуживания & $\begin{array}{l}\text { Повторная смазка - каждые } 12 \text { мес. }(0,75 \text { чел-час) } \\
\text { Замена масла в трансмиссии - каждые три года } \\
(1,25 \text { чел-час) }\end{array}$ \\
\hline 2 & Средняя наработка на отказ & 3,5 года \\
\hline 3 & $\begin{array}{l}\text { Средняя продолжительность } \\
\text { ремонта }\end{array}$ & $\begin{array}{l}\text { чривода) } \\
\text { Приводят компоненты, которые могут потребовать } \\
\text { ремонта или замены в течение 10-летнего срока }\end{array}$ \\
\hline
\end{tabular}

Системы слежения за Солнцем для размещения фотоэлектрических модулей с концентраторами должны обеспечивать реализацию преимуществ оптических устройств (концентраторов). Оптические устройства таких 


\section{ИННОВАЦИОННОЕ РАЗВИТИЕ НАУКИ: ФУНДАМЕНТАЛЬНЫЕ И ПРИКЛАДНЫЕ ПРОБЛЕМЫ}

фотоэлектрических модулей должны быть ориентированы перпендикулярно потоку прямого солнечного излучения с большей точностью, чем приемные поверхности традиционных плоских фотоэлектрических модулей.

Основным источником энергии для фотоэлектрических модулей с концентраторами является прямая составляющая солнечного излучения. Оптическое устройство разрабатывается специально для повышения плотности потока и/или изменения пространственного распределения солнечного излучения на приемнике. Если по каким-либо причинам требуемая ориентация оптической оси (приемной поверхности) нарушена, выходная мощность фотоэлектрических модулей с концентраторами существенно снижается.

Если фотоэлектрический модуль с концентратором концентрирует излучение в одном измерении, слежение необходимо выполнять только по одной оси. Если фотоэлектрический модуль/устройство с концентратором концентрирует излучение в двух измерениях, слежение необходимо выполнять по двум осям.

В фотоэлектрических модулях с концентраторами требования к точности слежения обычно обусловлены использованием излучения только внутри угла видимости концентратора. При ошибке наведения на Солнце меньшей, чем угол видимости, фотоэлектрические модули с концентраторами обычно обеспечивают не менее 90\% номинальной выходной мощности.

Одноосные (однокоординатные) системы слежения за Солнцем имеют одну ось вращения, расположенную в определенном направлении относительно горизонта или несколько осей вращения, расположенных в одном определенном направлении относительно горизонта.

Основные типы конструкций одноосных систем слежения за Солнцем:

- с горизонтальной осью вращения;

- с вертикальной осью вращения;

- с наклонной осью вращения.

Ось вращения одноосной системы слежения за Солнцем с горизонтальной осью вращения (рис. 1) горизонтальна по отношению к поверхности земли. 


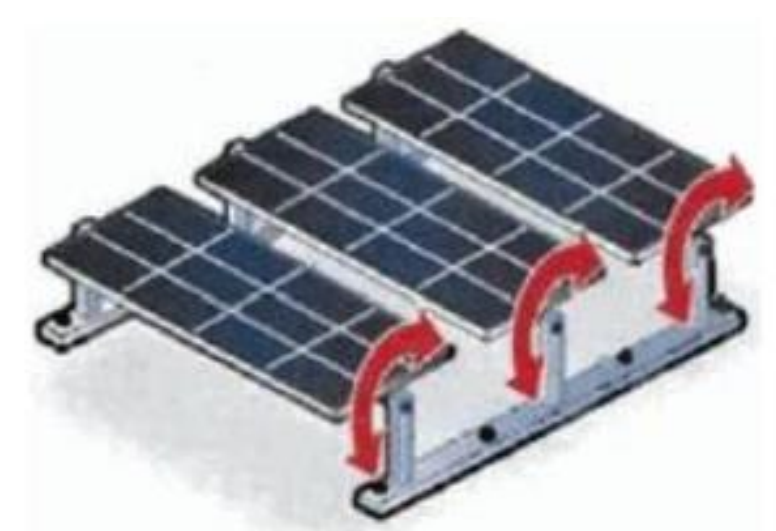

Рис. 1. Пример одноосной системы слежения за Солнцем с горизонтальной осью вращения $[1$, с. 8]

Горизонтальную ось вращения в соответствии с требованиями [1] рекомендуется устанавливать вдоль истинного северного меридиана. При использовании специальных алгоритмов слежения горизонтальную ось вращения можно установить в любом направлении.

Ось вращения одноосных систем слежения за Солнцем с вертикальной осью вращения (рис. 2) вертикальна по отношению к поверхности земли.

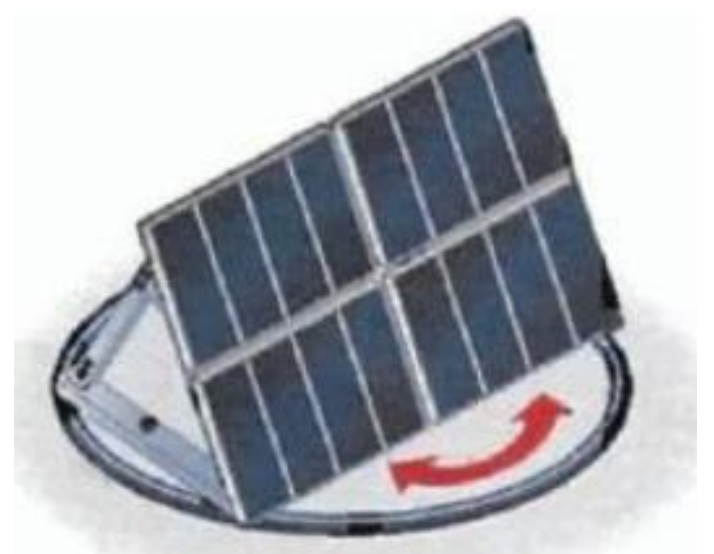

Рис. 2. Пример одноосной системы слежения за Солнцем с вертикальной осью вращения [1, с. 9]

При этом фотоэлектрические модули на таких системах слежения за Солнцем, как правило, стационарно закреплены под некоторым углом к горизонту. В течение дня такие системы слежения за Солнцем поворачиваются с востока на запад.

Все системы слежения за Солнцем с осью вращения, расположенной между горизонталью и вертикалью, рассматриваются как наклонные одноосные 


\section{ИННОВАЦИОННОЕ РАЗВИТИЕ НАУКИ: ФУНДАМЕНТАЛЬНЫЕ И ПРИКЛАДНЫЕ ПРОБЛЕМЫ}

системы слежения за Солнцем (рис. 3). Для того чтобы уменьшить ветровое сопротивление и высоту над землей поднятого края в таких системах слежения за Солнцем, угол наклона их оси относительно горизонта обычно ограничен.

Одноосная система слежения за Солнцем с осью вращения, параллельной полярной оси, является частным случаем одноосной наклонной системой слежения за Солнцем, у которой угол наклона оси относительно горизонта равен широте места установки. При этом вращение воспринимающей солнечное излучение поверхности проходит вокруг оси, направленной на полюс Мира. Такие системы также называют экваториальными системами слежения за Солнцем.

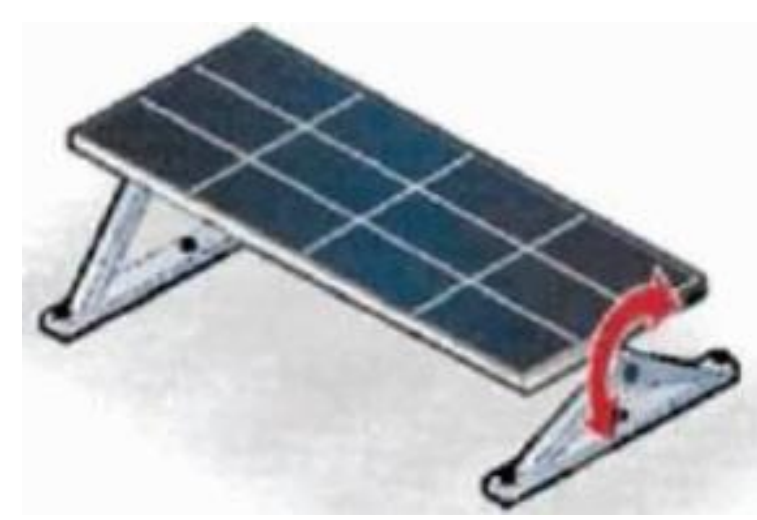

\section{Рис. 3. Наклонная одноосная система слежения за Солнцем [1, с. 9]}

Для характеристик фотоэлектрического модуля, установленного в системе слежения за Солнцем, важную роль играет ориентация его приемной поверхности по отношению к оси системы слежения за Солнцем.

У горизонтальных и наклонных одноосных систем слежения за Солнцем приемную поверхность фотоэлектрического модуля рекомендуется располагать параллельно оси вращения. В этом случае при выполнении слежения фотоэлектрический модуль следует по поверхности цилиндра с поворотной симметрией относительно оси вращения.

У вертикальных одноосных систем слежения за Солнцем приемную поверхность фотоэлектрического модуля рекомендуется устанавливать под углом по отношению к оси вращения.

В этом случае при выполнении слежения фотоэлектрический модуль следует по поверхности конуса с поворотной симметрией относительно оси вращения. 
Двухосные (двухкоординатные) системы слежения за Солнцем имеют две оси вращения, расположенные в разных направлениях относительно горизонта. Обычно эти оси перпендикулярны друг другу.

Основной осью считается ось, неподвижная относительно земли. Ось, положение которой определяется по отношению к основной, считается дополнительной осью.

Двухосные системы слежения за Солнцем могут иметь несколько осей вращения, расположенных в одном направлении относительно горизонта (как правило, в направлении дополнительной оси).

Соотношение между углами, определяющими положение Солнца, показано на рис. 4. Аналогично определяются ориентация приемной поверхности фотоэлектрического модуля и положение осей системы слежения за Солнцем.

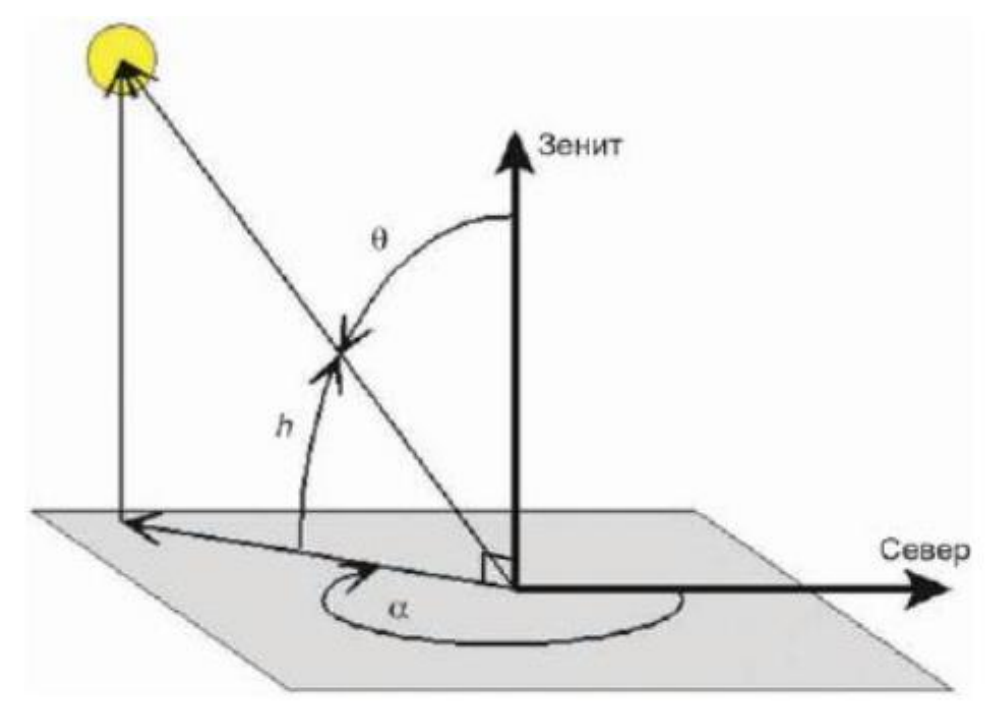

Рис. 4. Соотношение между углами, определяющими положение Солнца и положение осей (ориентацию) системы слежения за Солнцем: $\alpha$ - азимутальный угол; $\theta$ - угол между направлением на Солнце и зенит (угол относительно зенита); $h$ - угловая высота Солнца $[1$, с.10]

Азимутальный угол определяют в градусах "к востоку от севера", нулевой азимут направлен на север, а азимут $90^{\circ}$ направлен на восток.

Угол относительно зенита равен $0^{\circ}$, и соответственно угол наклона приемной поверхности фотоэлектрического модуля относительно горизонта (высота) равен $90^{\circ}$, когда приемная поверхность фотоэлектрического модуля 
перпендикулярна горизонту (рис. 5). Угол относительно зенита $\theta=90^{\circ}$ и $\beta=0^{\circ}$, когда фотоэлектрический модуль занимает горизонтальное положение. Соотношение угла наклона и угла падения на горизонтальную поверхность (угла относительно зенита) $\beta=90^{\circ}-\theta$.

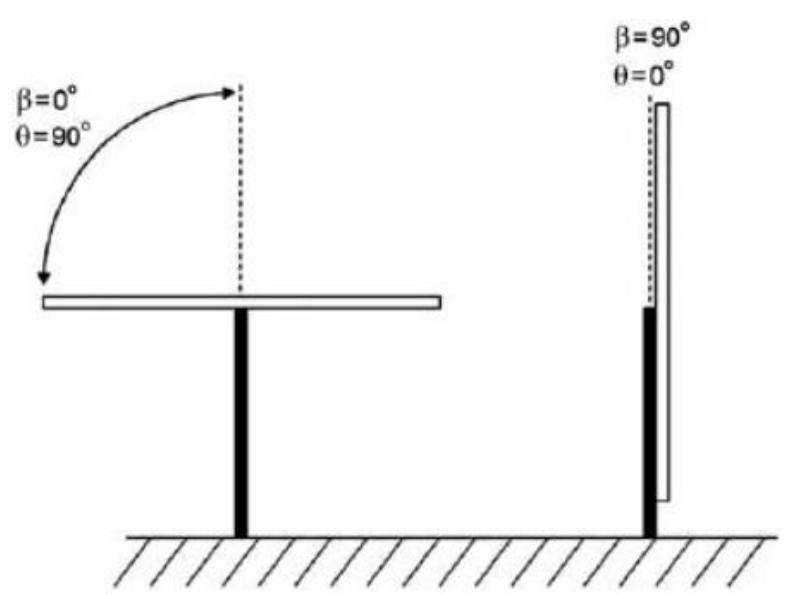

\section{Рис. 5. Соотношение между углом наклона приемной поверхности к горизонту (высотой) и углом относительно зенита $[1$, с.10]}

Угловая высота Солнца соответствует углу наклона приемной поверхности относительно горизонта $\beta$ при условии, что солнечные лучи падают нормально к приемной поверхности.

Приведенные выше варианты определения углов поворота и знаков углов поворота являются общепринятыми для систем слежения за Солнцем, однако допустимы и другие варианты, в этом случае следует приводить полное описание определения углов поворота и знаков углов поворота. Например, диапазон перемещения системы слежения за Солнцем вокруг вертикальной оси может быть задан как "азимутальный от $+20^{\circ}$ до $+340^{\circ}$ " или в другом варианте, как "азимутальный $\pm 160^{\circ}$ от юга".

Конструкции двухосных систем слежения за Солнцем различаются ориентацией основной оси относительно поверхности земли и подразделяются на типы:

- с горизонтальной основной осью вращения;

- с вертикальной основной осью вращения;

- c наклонной основной осью вращения. 
У двухосных систем слежения за Солнцем с горизонтальной основной осью (рис. 6) основная ось горизонтальна по отношению к поверхности земли. Дополнительная ось при этом обычно перпендикулярна основной оси.

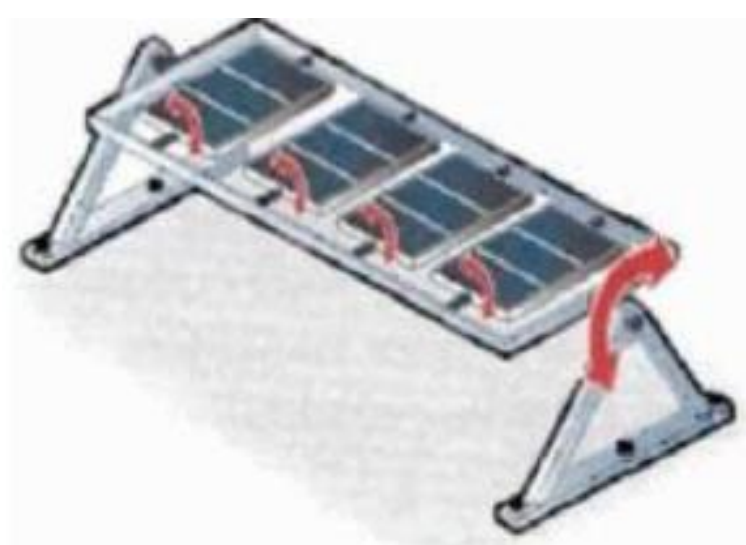

Рис. 6. Пример двухосной системы слежения за Солнцем с горизонтальной основной осью [1, с.11]

Основную ось вращения двухосных систем слежения за Солнцем с горизонтальной основной осью в соответствии с рекомендуется устанавливать вдоль истинного северного меридиана или линии широты "восток-запад". При использовании специальных алгоритмов слежения горизонтальную ось вращения можно установить в любом направлении.

У двухосных систем слежения за Солнцем с вертикальной основной осью (рис. 7) основная ось вертикальна по отношению к поверхности земли. Дополнительная ось при этом обычно перпендикулярна основной оси.

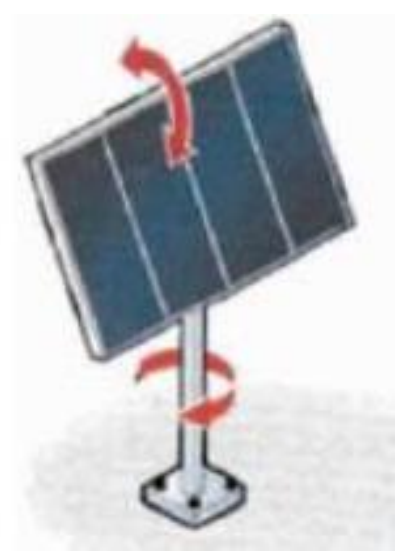

Рис. 7. Пример двухосной системы слежения за Солнцем с вертикальной основной осью [1, с.11] 
Система слежения за Солнцем, показанная на рис. 7, является азимутально-зенитальной системой слежения за Солнцем.

В качестве примера на рис. 8 представлена оригинальная конструкция крышной солнечной микроэлектростанции с азимутальным и зенитальным слежением за Солнцем [3, 4]. Солнечная микроэлектростанция с азимутальным и зенитальным слежением за солнцем включает в себя основание 1, на котором с южной и северной стороны на шарнирах 2 установлена горизонтальная площадка 3.

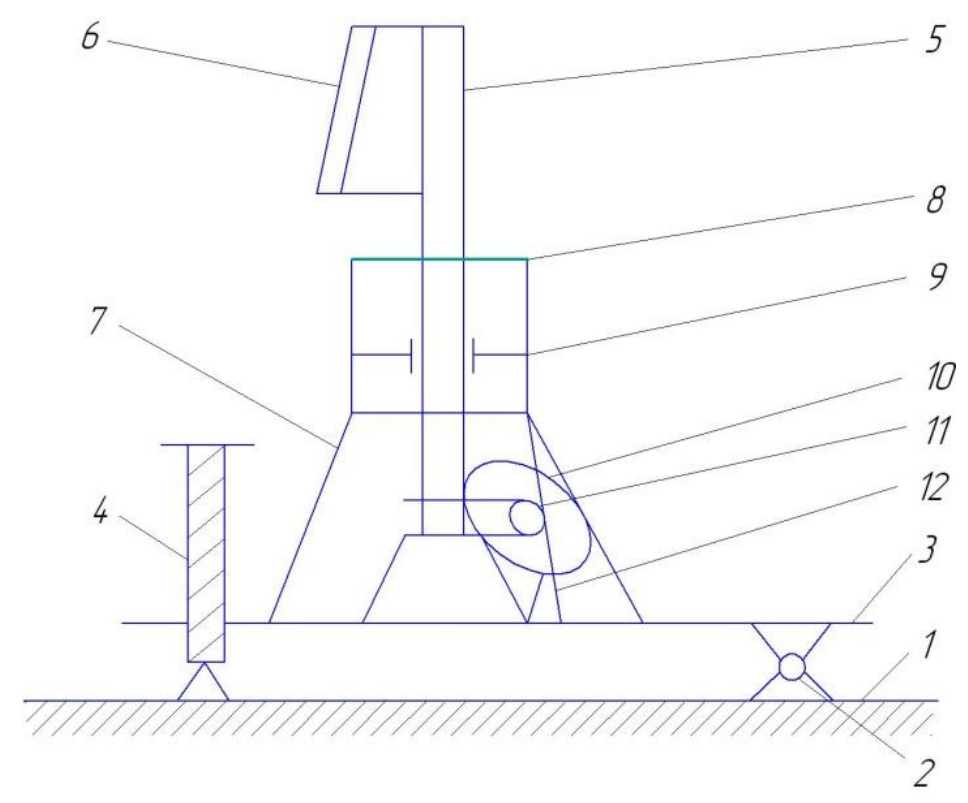

Рис. 8. Общий вид солнечной микроэлектростанции с азимутальным слежением за солнцем: 1 - основание; 2 - шарниры; 3 - горизонтальная площадка; 4 - винтовой домкрат; 5 - вертикальный вал; 6 - солнечная батарея; 7 -крестовина; 8 - диск микровыключателей; 9 - контактные кольца; 10 - зубчатое колесо; 11- червячный вал; 12 - электропривод

С южной стороны площадка 3 снабжена винтовым домкратом 4.

На горизонтальной площадке 3 установлен вертикальный вал 5 , на котором закреплена солнечная батарея 6 , а вал 5 центрируется крестовиной 7 , закрепленной на площадке 3. На крестовине 7 закреплен диск 8 микровыключателей (на рисунке не показано), а на валу 5 ползуна установлены контактные кольца 9. Снизу вал 5 снабжен зубчатым колесом 10 с червячным валом 11, который связан с валом электропривода 12. 
Электрическая схема солнечной электростанции (рис. 9) с азимутальным слежением за солнцем включает в себя солнечную батарею $B L 1$, вырабатывающую солнечную расчетную электрическую энергию заданного напряжения, допустим 220 В постоянного тока.

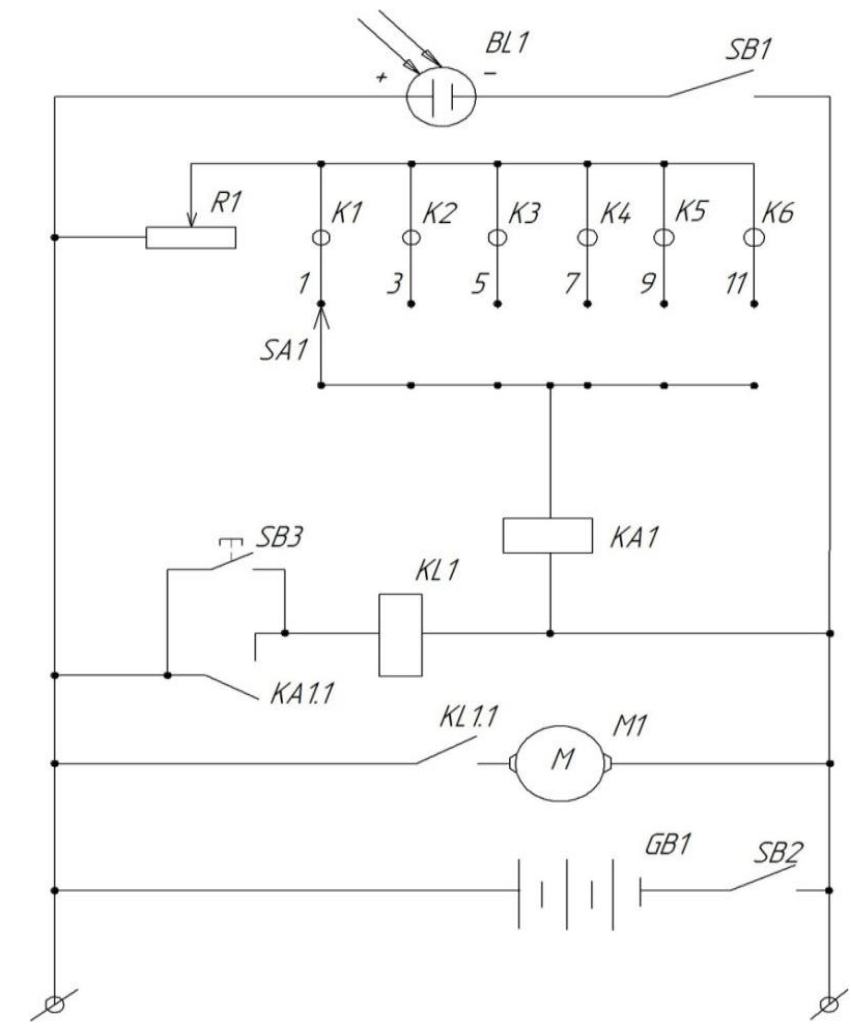

Рис. 9. Электрическая схема солнечной микроэлектростанции с азимутальным слежением за солнцем: $B L 1$ - солнечная батарея; $G B 1$ - аккумулятор; $R 1$ - потенциометр; $K$ - микровыключатели;

\section{$M 1$ - электропривод}

Через потенциометр переменного сопротивления (реостат) $R 1$ на циферблат контактных часов через цифру которых $(1,3,5,7,9$ и 11), подводится напряжение фазы, при этом в каждую цепь их питания включены контакты микровыключателей $K$, расположенных равномерно, в соответствии с циферблатом часов на диске 8.

На контактную часовую стрелку $S A 1$ через контактные кольца 9 подключена обмотка малоточного реле $K A 1$ на минус напряжения. Через его нормально разомкнутый контакт KA1.1 в цепь питания подключена обмотка силового реле KL1, нормально разомкнутые контакты KL1.1 которого 


\section{ИННОВАЦИОННОЕ РАЗВИТИЕ НАУКИ: ФУНДАМЕНТАЛЬНЫЕ И ПРИКЛАДНЫЕ ПРОБЛЕМЫ}

включены в цепь питания электропривода, при этом фазы плюс и минус напряжения солнечной батареи $B L 1$ снимаются через контактные кольца 9.

Между фазами в сеть питания подключен аккумулятор $G B 1$ для аккумулирования электрической энергии.

Солнечная микроэлектростанция с вырабатываемой мощностью до 10 кВ·А обладает простой системой слежения за положением солнца, обладает повышенной энергоэффективностью $[5,6]$, и пригодна для установки на крышах частных домов, промышленных зданий и сооружений для децентрализованных потребителей.

У двухосной системы слежения за Солнцем с наклонной основной осью основная ось установлена между горизонталью и вертикалью, наклонно по отношению к поверхности земли. Дополнительная ось при этом обычно перпендикулярна основной оси.

Для характеристик фотоэлектрического модуля, установленного в системе слежения за Солнцем, важную роль играет ориентация его приемной поверхности по отношению к осям системы слежения за Солнцем.

У двухосных систем слежения за Солнцем приемную поверхность фотоэлектрического модуля рекомендуется устанавливать параллельно дополнительной оси вращения.

Рассмотрим следующие параметры систем слежения за Солнцем: допуски по положению основной оси и дополнительной оси, люфты, жесткость, диапазон перемещения и мгновенная ошибка наведения.

Допуском по положению основной оси является полное допустимое отклонение фактического положения основной оси от ее заданного положения (т.е. вертикального, горизонтального или наклонного с заданным углом наклона) после завершения монтажа системы слежения за Солнцем (рис. 10). 


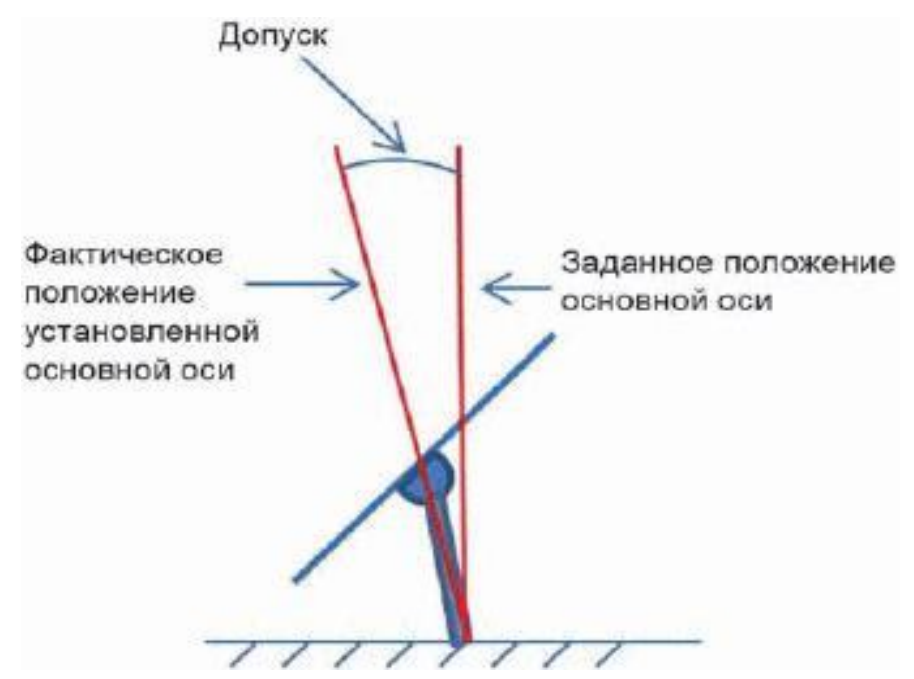

\section{Рис. 10. Пример допуска по положению основной оси для двухосной системы слежения за Солнцем с вертикальной основной осью [1, с. 16]}

Допуск, показанный на рис. 10, может быть задан в миллирадианах или градусах, и использоваться в качестве способа указания точности установки основной оси. Например, изготовитель может указать, что система слежения за Солнцем будет функционировать согласно паспортным данным при установке основной оси в пределах $1^{\circ}$ от номинального положения.

Допуском по положению дополнительной оси является полное допустимое отклонение в миллирадианах или градусах фактического положения дополнительной оси после завершения монтажа от ее заданного или идеального положения (п. 6.10.1.2 [1, с.16]).

Люфт системы слежения за Солнцем определяют как свободное перемещение в системе привода (п. 6.10 .13 [1, с.16]). Для конкретной системы слежения за Солнцем люфт задается относительно каждой оси вращения и как общее допустимое перемещение в градусах по каждой из осей. Люфт образуется в результате появления зазоров между поверхностями шестерен в передачах, перемещений шпилек или иных механических соединений, упругости жидкости в гидравлической системе и других механизмов, зависящих от конкретной системы, и может явственнее проявляться при сильном ветре. Люфт определяется по результатам испытаний.

Жесткость системы слежения за Солнцем обратно пропорциональна деформации конкретной части под нагрузкой (п. 6.10 .14 [1, с.17]). Жесткость системы слежения за Солнцем обеспечивается закреплением системы слежения за Солнцем на земле или на установленной на земле опорной конструкции 


\section{ИННОВАЦИОННОЕ РАЗВИТИЕ НАУКИ: ФУНДАМЕНТАЛЬНЫЕ И ПРИКЛАДНЫЕ ПРОБЛЕМЫ}

(основании), которая может рассматриваться как имеющая бесконечную жесткость (например, металлическая плита на бетонном полу), установкой рычагов, соосных с осями вращения, и их перемещением под воздействием внешней силы. На жесткость влияют система передач привода, рама (установочная конструкция) и закрепленные на ней фотоэлектрические модули, а также фундамент/основание.

Жесткость и крутильная жесткость трансмиссии определяются по результатам испытаний.

Диапазон перемещения определяется максимальным допустимым перемещением по каждому направлению по каждой из осей (п. 6.10.2 [1, c.17]). Например, диапазон перемещения может быть по азимуту $\pm 135^{\circ}$ от истинного юга (или в приведенной выше системе координат от $+45^{\circ}$ до $+315^{\circ}$ к востоку от севера) по основной вертикальной (азимутальной) оси и от $0^{\circ}$ до $90^{\circ}$ по высоте по дополнительной горизонтальной (зенитальной) оси.

Диапазон перемещения может обеспечиваться не только приводом. Например, чтобы ограничить диапазон перемещения для обеспечения безопасности или предотвращения затенения, могут применяться концевые выключатели или ограничение перемещения программными средствами. В том случае, когда управление системой слежения за Солнцем осуществляется блоком управления, диапазон перемещения определяется как максимальный диапазон перемещения, который достигается как программными, так и механическими средствами.

Диапазон перемещения проверяют по результатам испытаний.

Ошибкой наведения системы слежения за Солнцем является угол между требуемым направлением падения солнечных лучей на приемную поверхность фотоэлектрического модуля (в большинстве случаев они должны падать нормально к приемной поверхности фотоэлектрического модуля) и направлением на Солнце в данный момент времени (рис. 11). 


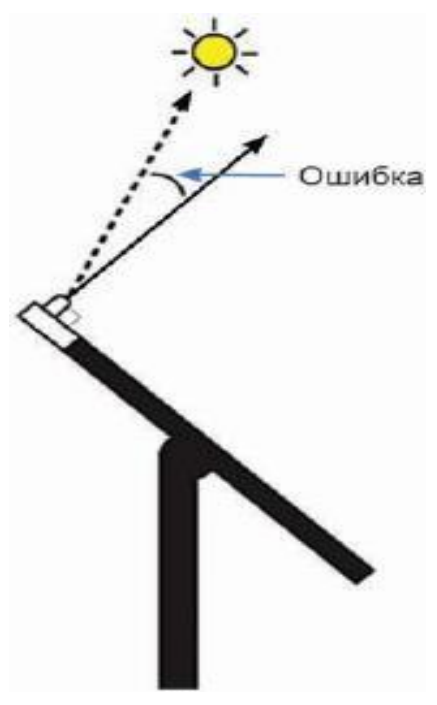

Рис. 11. К определению ошибки наведения системы слежения за Солнцем $[1$, c. 17]

Ошибка наведения определяется не столько точностью работы какойлибо одной подсистемы (такой как коробка передач, программа или блок управления), сколько объединением всех ошибок подсистем (п. 6.10.3 [1, с.17]).

Мгновенная ошибка наведения системы слежения за Солнцем не должна быть больше ее минимально допустимой точности слежения, указанной в паспортных данных. Мгновенная ошибка наведения определяется по результатам испытаний.

Упрощенный алгоритм определения диапазона точности слежения за Солнцем составлен на основе медианной оценки точности:

1) «Точность системы слежения за Солнцем (лучшая медианная)» принимается по значению медианной точности при слабом ветре и наименьшем отклонении. Например, это значение равно $0,4^{\circ}$.

Это один из вариантов быстрого получения значения ошибки для «обычных хороших условий при наименьшем отклонении»;

2) «Точность системы слежения за Солнцем (худшая медианная)» принимается по значению 95-го процентиля точности при сильном ветре и наибольшем отклонении. Например, это значение равно $1,4^{\circ}$. Это один из вариантов получения единственного значения в качестве «ошибки наихудшего случая» при оценке конструкции, хотя она и не является абсолютно наихудшим возможным случаем (это сделано преднамеренно, для того чтобы пренебречь влиянием одного или двух редко случающихся исключительных значений). 
Два этих значения могут быть объединены в упрощенную оценку диапазона точности «медианная точность слежения: лучшая — худшая» и точность слежения может быть заявлена как «диапазон медианной точности слежения от $0,4^{\circ}$ до $1,4^{\circ}$ ».

Дополнительно мгновенная ошибка наведения может быть представлена в виде гистограммы, показывающей частоты различных значений ошибки за весь период испытаний, как показано на рис. 12.

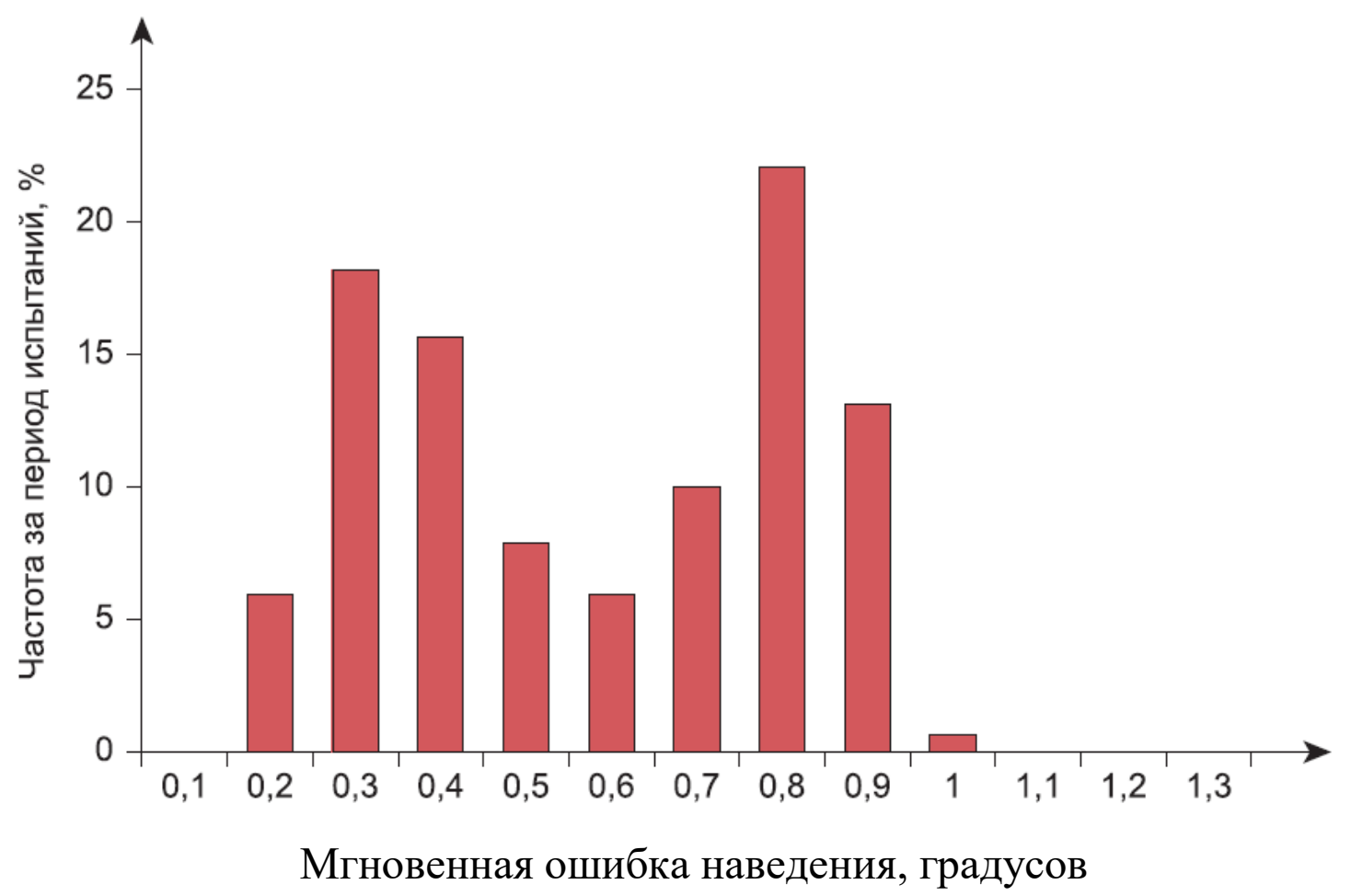

Рис. 12. Пример распределения частоты мгновенной ошибки наведения за весь период испытаний $[1, \mathbf{c . 5 9}]$

Данные о мгновенной ошибке наведения могут быть объединены с данными по энергетической освещенности прямого нормального солнечного излучения для получения графика, где измеренная ошибка наведения взвешивается значениями фактической энергетической освещенности прямого нормального солнечного излучения на приемную поверхность фотоэлектрических модулей, установленных на системе слежения за Солнцем.

Далее выполняют сортировку полученных данных об ошибке наведения по ее возрастанию. 
Для каждой ошибки наведения рассчитывают интеграл (или накопленную сумму) значений энергетической освещенности прямого нормального солнечного излучения до значения мгновенной ошибки наведения и строят график, подобный приведенному на рис. 13.

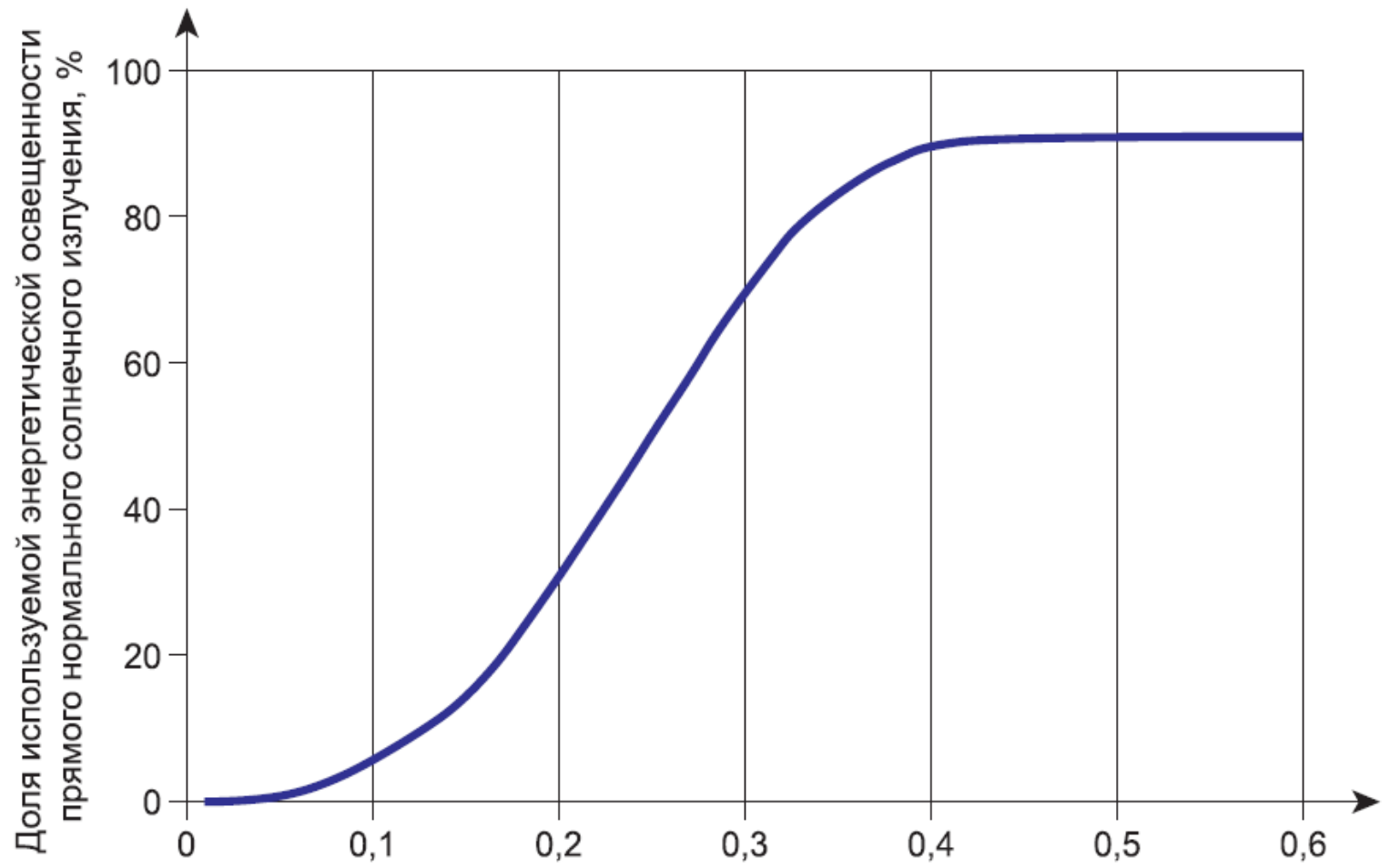

Мгновенная ошибка наведения, градусов

Рис. 13. Энергетическая освещенность прямого нормального солнечного излучения на приемную поверхность в зависимости от мгновенной ошибки наведения $[1$, с.60]

Аналогично можно выполнить группировку исходных данных по интересующему параметру (например, скорости ветра) и выполнить указанную выше процедуру отдельно для каждой группы и получить результирующий график (рис. 14). 


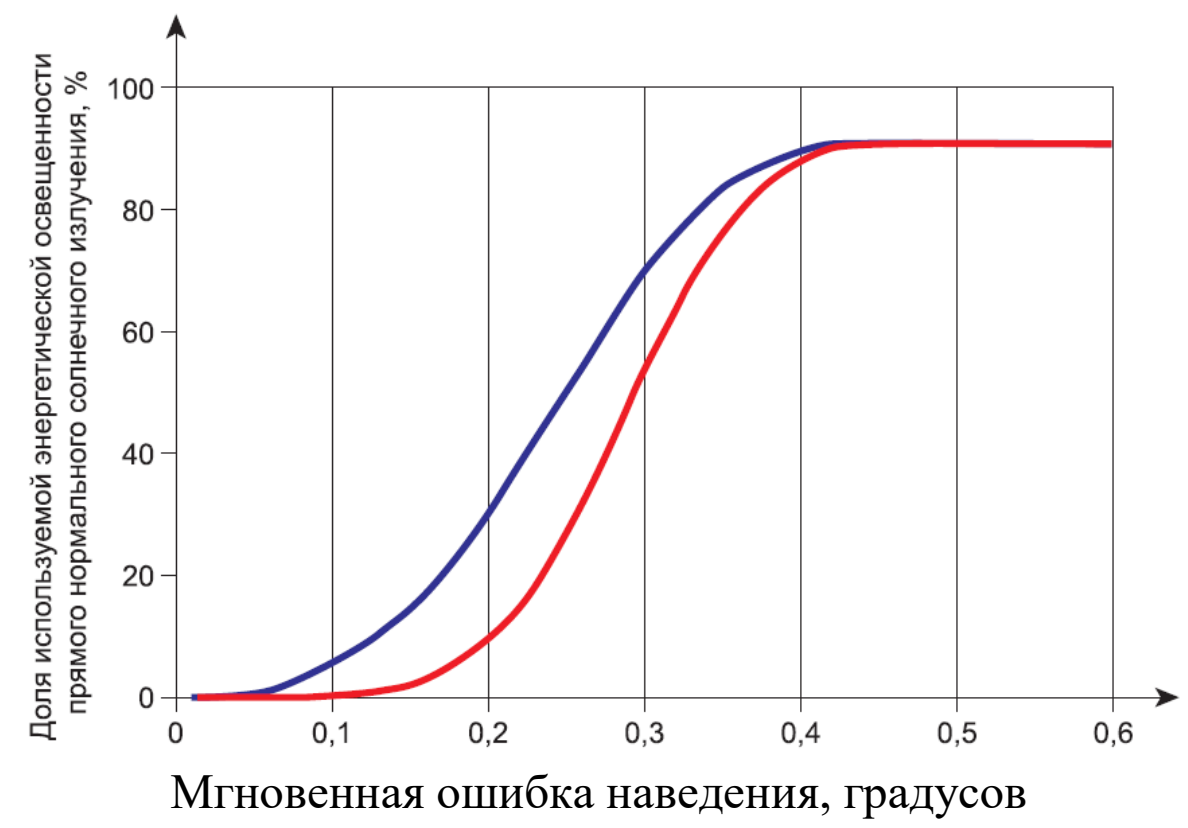

— Слабый ветер

— Сильный ветер

\section{Рис. 14. Энергетичес кая ос вешенность прямого нормального с олне чног о из лучения на приемнуюповерхность в завис имости от мг новенной ошиби наведения с раз делением по скорости ветра [1, c.60]}

Блок управления системы слежения за Солнцем включает электронную аппаратуру управления: микропроцессор, пускозащитную аппаратуру двигателей, блоки питания и преобразования, аппаратуру передачи данных и т.п. В него обычно не входят датчики положения, такие как аналого-цифровые преобразователи и концевые выключатели.

В общем случае система слежения за Солнцем включает следующие датчики:

- датчики, которые обеспечивают замкнутый контур управления (датчики положения Солнца, измерители выходной мощности фотоэлектрического модуля);

- датчики, которые обеспечивают точное позиционирование трансмиссии (аналого-цифровые преобразователи, угломеры);

- датчики, которые передают данные о погоде (температура, скорость и направление ветра и т.п.) либо с целью управления системой, либо для регистрационных целей. 
Слежение за Солнцем, как правило, может выполняться по одному из следующих алгоритмов: непрерывно, импульсно, непрерывно-импульсно, по заранее заданной траектории. Основные режимы, обеспечиваемые системой управления:

- режим автоматического слежения;

- режим ручного наведения (по крайней мере для пусконаладочного режима);

- режим управления слежением с внешнего компьютера.

В системе слежения за Солнцем может отсутствовать режим автоматического слежения или режим управления слежением с внешнего компьютера или могут быть дополнительные режимы работы.

Пассивное слежение за Солнцем обычно основано на использовании воздействия внешней среды с тем, чтобы вызвать изменение плотности жидкости. Изменение плотности жидкости создает внутренние силы, в результате действия которых происходит изменение положения установленного оборудования (фотоэлектрических модулей).

При активном слежении за Солнцем для управления электрическими цепями и приводами (двигателями, гидравлическими устройствами и прочим) используется внешняя энергия.

Различают следующие виды управления:

- управление с разомкнутым контуром;

- управление с замкнутым контуром;

- смешанное управление;

- превентивное управление.

Разомкнутый контур в смысле управления системой слежения за Солнцем подразумевает алгоритм управления, в котором непосредственная обратная связь по фактической ошибке наведения отсутствует. Управление с разомкнутым контуром является активным способом слежения, при котором контур обратной связи с непосредственным определением положения Солнца или мощности фотоэлектрического модуля не используется. В другом варианте при таком способе управления для определения направления наведения и соответствующего управления приводами используются математические расчеты положения Солнца (на основе времени дня, даты, координат местности и т.п.). 
При управлении с разомкнутым контуром не предполагается отсутствие обратных связей от самих элементов привода. Приводы могут быть сервомоторами с датчиками, и управление ими может осуществляться блоком управления с обратной связью.

Управление с замкнутым контуром является активным способом управлением слежения, при котором для управления приводами и положением установленного оборудования используется некоторая обратная связь (например, от оптического датчика положения Солнца или по величине выходной мощности фотоэлектрического модуля).

Смешанное управление является также активным способом управлением, объединяющим математические расчеты положения Солнца и данные от некоторых датчиков, применяемых при управлении с замкнутым контуром.

Превентивное управление (возвратное слежение) относится к преднамеренному ориентированию фотоэлектрических модулей с отклонением от направления на Солнце. Обычно превентивное управление используется для того, чтобы избежать взаимного затенения соседних фотоэлектрических модулей / фотоэлектрических модулей соседних систем слежения за Солнцем ранним утром или на исходе дня при низком положении Солнца над горизонтом.

Одним из способов такого управления, позволяющим избежать взаимного затенения, является перемещение в утренние и вечерние часы всех расположенных друг за другом систем слежения за Солнцем в положение с углом наклона приемных поверхностей к горизонту меньшим, чем угол, при котором приемные поверхности перпендикулярны поступающему излучению. Утром, после того как вероятность затенения исчезает, системы переходят к слежению за Солнцем в обычном режиме (нормаль к приемным поверхностям совпадает с направлением прямого солнечного излучения с требуемой точностью).

Другим способом является приведение в утренние и вечерние часы систем слежения за Солнцем через ряд в неактивное положение с $90^{\circ}$ возвышением (горизонтальное положение) с тем, чтобы обеспечить оставшимся рядам поступление солнечного излучения без затенения.

Превентивное управление обычно применяется в тех случаях, когда для размещения фотоэлектрических модулей невозможно получить участок 
достаточно большой площади с тем, чтобы обеспечить их просторную установку без взаимного затенения ранним утром или на исходе дня.

Если в системе слежения за Солнцем устанавливают фотоэлектрические модули (устройства) с концентраторами, превентивное управление обычно не применяется.

Системы слежения за Солнцем разделяют на два основных типа по приведению в действие системы привода - индивидуальное и групповое.

При индивидуальном приведении в действие осуществляется независимое перемещение вокруг каждой из осей вращения каждой отдельной системы слежения за Солнцем в фотоэлектрической системе.

При групповом приведении в действие одним приводом осуществляются одновременно перемещения вокруг нескольких осей. Это может быть перемещение вокруг нескольких осей одной системы слежения за Солнцем или одновременное перемещение вокруг всех горизонтальных и/или всех вертикальных осей нескольких систем слежения за Солнцем в фотоэлектрической системе.

В соответствии с [1] различают два вида положения системы слежения за Солнцем: штормовое положение и положение для обслуживания.

Штормовое положение - это положение, в которое переводится система слежения за Солнцем с тем, чтобы избежать нагрузок, которые могут повредить систему слежения за Солнцем или устанавливаемое оборудование при наступивших или ожидаемых плохих погодных условиях, например, сильном ветре или сильном снегопаде. Штормовое положение предусматривается не у всех систем слежения за Солнцем, и требуемое штормовое положение может зависеть от конструкции системы слежения за Солнцем. У одной системы слежения за Солнцем может быть несколько штормовых положений (п.6.8.1 [1, с.14]).

Положение для обслуживания - это положение, в которое переводится система слежения за Солнцем при необходимости выполнения таких операций, как чистка, установка фотоэлектрических модулей или техобслуживание. Такое положение может быть тем же, что и штормовое положение, или отличным от него, кроме того, у одной системы слежения за Солнцем может быть несколько положений для обслуживания. Положение для обслуживания у системы слежения за Солнцем может отсутствовать. В положении для обслуживания должна быть установлена защитная блокировка, предотвращающая внезапное 


\section{ИННОВАЦИОННОЕ РАЗВИТИЕ НАУКИ: ФУНДАМЕНТАЛЬНЫЕ И ПРИКЛАДНЫЕ ПРОБЛЕМЫ}

перемещение системы слежения за Солнцем без команды технического персонала. Защитная блокировка может быть выполнена различными способами, но во всех случаях для выполнения разблокирования необходимы специальные действия технического персонала (п.6.8.2 [1, с.14]).

\section{Заключение.}

Нормативные требования к системам слежения за Солнцем в составе автономных энергетических установок с фотоэлектрическими модулями способствуют получению полной информации о конкретной системе слежения за Солнцем и могут быть использованы при создании солнечных систем других типов. Применение упрощенного алгоритма определения точности слежения за Солнцем на основе медианной оценки способствует быстрому определению ошибки наведения, выходящей за пределы диапазона медианной точности слежения от $0,4^{\circ}$ до $1,4^{\circ}$.

\section{Список литературы}

1. ГОСТ Р 57229-2016 (МЭК 62817: 2014) Системы фотоэлектрические Устройства слежения за Солнцем. Технические условия. Photovoltaic systems. Solar trackers. General specifications / введ. 01.09.2017; акт. 01.01.2021. - Москва: Стандартинформ, 2016. - 62 с.

2. ГОСТ Р 51997 -2000 Нетрадиционная энергетика. Модули солнечные фотоэлектрические. Типы и основные параметры / введ. 01.01.2001; акт. 01.01.2021. - ИПК: из-во стандартов, 2000. - 8 с.

3. Андрианова Л.П. Энергообеспечение децентрализованных потребителей на основе крышных ветродвигателей и солнечных электростанций / Л.П. Андрианова, В.Ю. Кабашов // Международный техникоэкономический журнал. -№1, 2019. - Москва: ООО Спектр. - 87 с. - С. $72-78$.

4. Андрианова, Л.П. Солнечная электростанция: патент на полезную модель № 94379 / Л.П. Андрианова Л.П. [и др.]. - № 2010103657/22; заявл. 03.02.10; опубл. 20.05.10, Бюллютень изобретений № 14. -2 с.

5. Андрианова, Л.П. Повышение эффективности солнечной электростанции / Л.П. Андрианова, А.Е. Тукбаева // Механизация и электрификация сельского хозяйства. - 2010. - № 13. - С. 25-26.

6. Андрианова, Л.П. Солнечные энергетические установки с повышенной энергетической эффективностью / Л.П. Андрианова, А.Е. 
Усманова // Актуальные проблемы энергообеспечения предприятий. Материалы международной науч. - практ. конф., проводимой в рамках XIV Российского энергетического форума.-Уфа: Башкирский ГАУ, 2014. С. 18 - 23.

( Л.П. Андрианова, Л.А. Рябишина, Р.Т. Хазиева, 2021 